\title{
Correlation of Cord Lactate with Cord pH as a Morbidity Predictor in Term Neonates Delivered with Non-Reassuring Fetal Heart Status
}

\author{
Aluru Ananya ${ }^{\oplus 1}$, Kanta Kumari PML ${ }^{2}$, B Vijayalakshmi ${ }^{\oplus 3}{ }^{3}$, R Chandrasekhar ${ }^{\odot 4}$, Naga Saritha Kolli ${ }^{\odot 5}$ \\ ${ }^{1}$ Resident, Department of Pediatrics, NRI Medical College and General Hospital, Chinakakani, Guntur, Andhra Pradesh, India, ${ }^{2}$ Associate Professor, Department of \\ Pediatrics, NRI Medical College and General Hospital, Chinakakani, Guntur, Andhra Pradesh, India, ${ }^{3}$ Professsor \& HOD, Department of Pediatrics, NRI Medical College \\ and General Hospital, Chinakakani, Guntur, Andhra Pradesh, India, ${ }^{4}$ Professor, Department of Pediatrics, NRI Medical College and General Hospital, Chinakakani, \\ Guntur, Andhra Pradesh, India, ${ }^{5}$ Lecturer, Department of Community Medicine, NRI Medical College and General Hospital, Chinakakani, Guntur, Andhra Pradesh, India.
}

\section{Abstract}

Background: Perinatal asphyxia is accounting to $20 \%$ of neonatal mortalityin India. Cord lactate can be an alternative that is more readily available than cord $\mathrm{pH}$ and may help in early identification of birth asphyxia in resource limited settings. The aim of the current study is to correlate cord lactate levels with cord $\mathrm{pH}$ in term neonates with non-reassuring fetal heart status and thereby its use as a surrogate for cord pH. Subjects \& Methods: Study design: Cross-sectional study. Setting: Neonatology unit at NRI general hospital, Chinakakani from August 2018 to July 2019. Study participants: All singleton term neonates delivered by assisted vaginal delivery or emergency caesarean section due to non-reassuring fetal heart status. Umbilical cord blood gas and lactate was obtained. Lactate was analysed by colorimetric method. Results: A total of 74 neonates were included. An analysis of cord $\mathrm{pH} \&$ lactate, using correlation coefficient showed statistically significant p-values. Cord lactate was found to be statistically significant predictor for admission to NICU, post resuscitation care, invasive/noninvasive ventilation, and therapeutic hypothermia on multiple logistic regression analysis. Cord Lactate was found to have an Area under the curve (AUC) of 0.88 with no significant difference to cord $\mathrm{pH}$ on ROC curve analysis. Conclusion: Cord Lactate can be used as an objective test in predicting the neonates requiring NICU admission for morbidities related to fetal hypoxia similar to that of cord $\mathrm{pH}$ in term neonates.

Keywords: Term neonates, cord $\mathrm{pH}$, cord lactate, indicator of fetal hypoxemia, non-reassuring fetal heart status

Corresponding Author: Kanta Kumari PML, Associate Professor, Department of Pediatrics, NRI Medical College and General Hospital, Chinakakani, Guntur, Andhra Pradesh, India.

E-mail: kantakumari@hotmail.com

Received: 04 August 2020

Revised: 21 September 2020

Accepted: 30 September 2020

Published: 10 October 2020

\section{Introduction:}

Birth asphyxia accounts for an estimated 9, 00,000 deaths each year and is one of the primary causes of early neonatal mortality. ${ }^{[1]}$ The incidence of perinatal Asphyxia is $8.4 \%$ of all live births, and is accounting to $20 \%$ of neonatal mortality and $11 \%$ of under-5 mortality in India. ${ }^{[2,3]}$

Fetal distress is described as an altered fetal physiology, leading to disruption of normal fetal oxygenation ranging from mild hypoxia to profound fetal asphyxia leading to metabolic acidosis, ${ }^{[4]}$ ultimately causing permanent injury or death within a very short period. Fetal distress is usually detected by cardiotocography (CTG) or non-stress test (NST) which though highly sensitive, lacks specificity. ${ }^{[5]}$ APGAR scoring at birth is a semi quantitative measurement with variable inter and intra observer reliability \& hence cannot be used to describe birth asphyxia accurately. ${ }^{[6]}$ In this era of Pediatricians and Obstetricians being increasingly sued for Medico-legal negligence in cases of Birth asphyxia and developmental delay, there is a need for objective tests to substantiate fetal hypoxia.

Cord $\mathrm{pH}$ and Base excess (BE) in blood gas analysis are established objective tests for assessment of fetal asphyxia and along with the clinical picture, it helps in making appropriate decisions about care after birth. ${ }^{[7,8]}$ Low cord $\mathrm{pH}$ is substantially associated with neonatal mortality and morbidity and later cerebral palsy in childhoodbut requires immediate analysis, ${ }^{[9]}$ and expensive equipment which may not be available near all delivery rooms. High lactate levels are related to fetal metabolic anaerobic glycolysis occurring during hypoxia. Cord lactate can be an alternative to arterial blood gas and it may help in early identification of birth asphyxia in resource limited settings. 
Several animal and human studies have addressed the question of lactate origin when fetal lactate concentration is increased. Piquard et al, ${ }^{[10,11]}$ described several findings strongly indicating fetal origin both in steady-state labors as well as in labors complicated by acute stress conditions. Thus, a rapid rise in lactate concentration as a response to a relatively sudden development of hypoxia, as during labor, can be regarded as of fetal origin.

\section{Subjects and Methods}

This cross-sectional study was designed to compare cord lactate levels with cord $\mathrm{pH}$ in predicting NICU admission, post resuscitation care, noninvasive ventilation, invasive ventilation and therapeutic hypothermia.

\section{Inclusion criteria :}

All Term (>37 weeks) non-anomalous singleton neonates delivered through assisted vaginal delivery(AVD) or emergency cesarean section(CS) with an indication of nonreassuring fetal heart status.

The parents were explained about the research, and written informed consent was obtained. Intrapartum CTG tracings were collected and categorized according to American college of Obstetrics \& Gynecology (ACOG) recommended3 tier system. Soon after birth, umbilical cord arterial blood was collected from a clamped segment of the cord into a preheparinized syringe for arterial blood gas analysis and into a $2 \mathrm{ml}$ plain container for lactate measurement. The sample was transferred to the central laboratory on an ice pack immediately. Arterial blood gas was analyzed using GEM Premier 3500 analyzer (Instrumentation laboratory) within 5 minutes quickly, while Lactate was measured by Colorimetric method on RANDOX IMOLA within 20 minutes of collection of the sample. The results were recorded. APGAR scores were recorded at $1 \mathrm{~min}, 5 \mathrm{~min}$, and 10 minute. The neonate was followed up till discharge from the hospital and details of NICU admission and requirement of post-resuscitation care, non- invasive ventilation, invasive ventilation, therapeutic hypothermia if present were recorded.

\section{Statistical Analysis:}

Data was analyzed using Medcalc v19.1.Pearson Correlation coefficient for cord lactate \& cord $\mathrm{pH}$ and cord lactate \& cord $\mathrm{BE}$ was done. Multiple logistic regression analysis for the variables was done. In order to comment on which test is better, Receiver-Operating Characteristic (ROC) curves for NICU Admission and its accuracy is measured by the area under the curve (AUC). Comparison of ROC curves of cord $\mathrm{pH}$, cord lactate and cord BE for NICU admission was done. $\mathrm{P}$-value $<0.05$ was taken as statistically significant.
Results:

Out of 1836 deliveries from August 2018 - July 2019, 86 term neonates were delivered by AVD or emergency CS due to nonreassuring fetal heart status. Cord arterial gas and cord lactate could not be obtained for seven neonates; five neonates left against medical advice, and finally, a total of 74 term neonates have been included in the study.

The mean birth weight of the study population is $2.78 \mathrm{~kg}$. Out of the 74 neonates, 36 (49\%) were male, and $38(51 \%)$ were female. Of the fetal heart patterns, $55.4 \%$ belonged to Category II, while $44.6 \%$ belonged to Category III according to ACOG recommended 3 tier systems. Among the 74 Study neonates, $59(80 \%)$ were delivered through Emergency CS, while $15(20 \%)$ were delivered through AVD by use of either forceps or vacuum. $56(75.6 \%)$ neonates were Appropriate for Gestational age (AGA), and 18 (24.4\%) were Small for Gestational age (SGA).

Twenty-seven neonates were admitted to NICU, while 47 neonates were shifted to the mother's side immediately after birth. Among the neonates, 9.4\% required post-resuscitation care, $12.1 \%$ required non-Invasiveventilation, $16.2 \%$ required invasive ventilation, $12.1 \%$ required therapeutic hypothermia. $97 \%$ got discharged home, and death occurred in 3\%.

Pearson's correlation between cord $\mathrm{pH}$ and cord lactate levels, cord $\mathrm{BE}$ and cord lactate revealed highly significant correlations with coefficient $r=-0.7501$ ( $p$-value of $<0.0001$ ) and $\mathrm{r}=-0.7792(\mathrm{P}<0.0001))$ respectively.

The mean cord lactate was higher in neonates delivered through $\operatorname{AVD}(8.82 \mathrm{mmol} / \mathrm{lt})$ compared to those born through emergency CS $(6.59 \mathrm{mmol} / \mathrm{tt})$. However, independent samples T-test showed no significant difference in cord lactate levels $(p=0.06)$. The mean cord lactate of AGA was $6.83 \mathrm{mmol} / \mathrm{lt}$ while in SGA was $7.71 \mathrm{mmol} / \mathrm{lt}$ and the difference was not statistically significant $(\mathrm{p}=0.44)$.

On comparing 1-minute APGAR, 5-minute APGAR, 10minute APGAR, cord $\mathrm{pH}$, cord $\mathrm{BE}$ and cord lactateas variables for primary outcome (NICU admission) and secondary outcomes (post-resuscitation care, non-invasive ventilation, invasive ventilation \& therapeutic hypothermia), the significant predictors obtained from multiple logistic regression analysis are as shown in [Table 1].

The ROC curves of cord $\mathrm{pH}$, cord $\mathrm{BE}$ and cord lactate for NICU admission are shown in [Figure 1]. The AUC of cord pH (0.93) was higher than cord lactate (0.88) with no significant statistical difference with each other $(p=0.250)$. The AUC of Cord lactate was similar to Cord BE (0.89).

The optimal cut off values with their respective sensitivity and specificity for cord $\mathrm{pH}$, cord $\mathrm{BE}$ and cord lactate are as shown in [Table 2]. 


\begin{tabular}{llll}
\hline Table 1: Significant predictors of Primary and Secondary outcomes by multiple logistic regression analysis \\
\hline & Variables & P-value & Coefficient \\
\hline NICU Admission & Cord pH & 0.045 & -1.09 \\
\hline \multirow{2}{*}{ Post-resuscitation care } & Cord Lactate & 0.028 & 0.03 \\
& 1-minute APGAR & 0.009 & -0.029 \\
& 5-minute APGAR & 0.030 & 0.27 \\
\hline Non-Invasive ventilation & Cord Lactate & 0.006 & -0.04 \\
& 1-minute APGAR & 0.009 & 0.36 \\
& Cord pH & 0.03 & -1.07 \\
\hline Invasive ventilation & Cord Lactate & 0.01 & 0.04 \\
& 1-minute APGAR & 0.007 & -0.19 \\
& 5-minute APGAR & 0.013 & -0.21 \\
\hline & 10-minute APGAR & 0.009 & 0.35 \\
\hline Therapeutic Hypothermia & 5-minute APGAR & 0.004 & 0.03 \\
\hline & Cord pH & 0.0001 & -0.39 \\
\hline
\end{tabular}

Table 2: ROC curves of Cord pH, Cord BE and Cord Lactate for NICU admission

\begin{tabular}{|c|c|c|c|}
\hline & Cord pH & Cord BE & Cord Lactate \\
\hline $\begin{array}{l}\text { AUC(Area } \\
\text { Curve) }\end{array}$ & 0.93 & 0.89 & 0.88 \\
\hline $95 \% \mathrm{CI}$ & 0.853 to 0.979 & 0.807 to 0.957 & 0.790 to 0.948 \\
\hline p-value & $<0.0001$ & $<0.0001$ & $<0.0001$ \\
\hline Specificity & $81.2 \%$ & $89.6 \%$ & $77 . \%$ \\
\hline
\end{tabular}

\section{Discussion:}

As opined by the ACOG and AAP in Executive summary: Neonatal encephalopathy and neurologic outcome, no single strategy to identify HIE is infallible and will achieve $100 \%$ certainty of the cause of neonatal encephalopathy in all cases. ${ }^{[12]}$ An objective measurement of fetal hypoxia is required to increase understanding of its association with adverse neonatal outcomes and secondly to be able to predict those at risk for morbidity and mortality and to ensure appropriately focused interventions. ${ }^{[13-15]}$ White et al, ${ }^{[16]}$ suggested that a simple combination of the level of neonatal resuscitation and umbilical artery lactate values is an accurate method of predicting moderate-severe cases of HIE within minutes of delivery and thereby identifies neonates that may benefit from neonatal hypothermia as a neuroprotective therapy.
The existing data on the diagnostic accuracy comes from largely high-income countries. There is a need to assess the role of lactate as an inexpensive, simple and reliable tool in perinatal care of low- and middle-income countries, where the burden of both poor quality of care and poor neonatal outcomes is high. E. R. Allanson et al. in their study found that Umbilical lactate can be used in a middle-low resource setting as a measurement of intrapartum hypoxia, with reasonable sensitivity and specificity for the prediction of, or need for, resuscitation, admission to the nursery, and low Apgar scores. ${ }^{[17]}$ Duhan et al, ${ }^{[18]}$ reported a good negative predictive value of lactate for fetal hypoxia when done using the colorimetric method similar to the present study. Ours is one of the very few studies that looked at the significance of cord lactate in Indian population and more so in neonates with non-reassuring fetal heart status who were delivered by emergency CS or AVD. 


\begin{tabular}{|c|c|c|c|c|}
\hline \multirow[t]{2}{*}{ Comparative } & \multicolumn{2}{|c|}{ Cord Lactate with Cord pH } & \multicolumn{2}{|c|}{ Cord Lactate with Cord Base excess } \\
\hline & $\begin{array}{l}\text { Pearson Correlation } \\
\text { Coefficient (r) }\end{array}$ & P-value & $\begin{array}{l}\text { Pearson Correlation } \\
\text { Coefficient (r) }\end{array}$ & P-value \\
\hline Present Study & -0.750 & $<0.0001$ & -0.779 & $<0.0001$ \\
\hline Gjerris et al & -0.730 & $<0.001$ & -0.760 & $<0.001$ \\
\hline Labreque et al & -0.678 & $<0.001$ & -0.719 & $<0.001$ \\
\hline Linet et al & -0.693 & $<0.0001$ & -0.837 & $<0.0001$ \\
\hline Racinet et al & -0.750 & $<0.001$ & -0.790 & $<0.001$ \\
\hline $\begin{array}{l}\text { Allason ER et al. } \\
\text { Systematic review }\end{array}$ & -0.650 & $<0.001$ & -0.710 & $<0.001$ \\
\hline
\end{tabular}

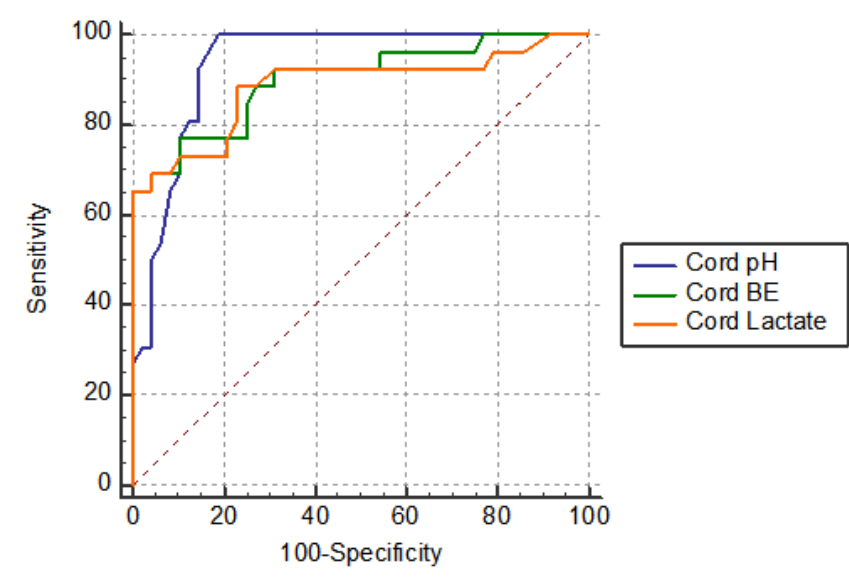

Figure 1: ROC curves of Cord pH, Cord BE and Cord Lactate for NICU admission

In contrast to the study done by Borruto $\mathrm{F}$ et al. ${ }^{[19]}$ and Natesan $\mathrm{S},{ }^{[20]}$ mode of delivery did not have significant influence on cord lactate levels in our study. Cord lactate correlated well with cord $\mathrm{pH}$ and Base excess with a p-value of $<0.0001$ in our study. These findings are similar to the studies by Gjerris et al. ${ }^{[21]}$ Labreque et al. ${ }^{[22]}$ Linet et al. ${ }^{[23]}$ and Racinet et al. ${ }^{[24]}$ Most of the studies were done using a handheld lactate meter while in our study lactate levels were analyzed by colorimetric method. The present study was done selectively on term neonates with non-reassuring fetal heart status while the population in the above studies constituted term neonates with and without non reassuring fetal heart status. However, the correlation between cord lactate with cord $\mathrm{pH}$ and cord $\mathrm{BE}$ was still similar in all the studies. Allason ER et al. ${ }^{[25]}$ did a systematic review of 6 studies on Cord lactate and had a total of 8128 participants. The pooled effect size for Cord Lactate with Cord $\mathrm{pH}$ was -0.650 with $\mathrm{p}$-value $<0.001$, and for Cord Lactate with Cord BE was -0.710 with p-value $<0.001$, which was statistically significant, and similar results were observed in the current study. [Table 3]

Cord Lactate consistently was the only predictor of both primary outcome and all the secondary outcomes when compared to other variables in our study. Cord lactate at a cut off value of $\geq 5.5 \mathrm{mmol} / \mathrm{lt}$ has good sensitivity and specificity (with AUC of 0.88) similar to cord $\mathrm{pH}$ and cord Base excess. ER Allanson et al. ${ }^{[17]}$ reported a cord lactate cut-off value of $5.65 \mathrm{mmol} / \mathrm{lt}$ for NICU admission with AUC 0.61, while Tuuli et al. ${ }^{[26]}$ reported $3.9 \mathrm{mmol} / \mathrm{lt}$ with AUC of 0.84 . The difference in cut-off values might be due to differences in assays and study populations. Patil SS et al. ${ }^{[27]}$ reported a cord lactate cut-off value of $5 \mathrm{mmol} / \mathrm{lt}$ for NICU admission in neonates with non-reassuring fetal heart status with an AUC of 0.878 which was comparable to our study.

\section{Conclusion}

In conclusion, cord lactate can be a potentially relevant, inexpensive and simple test for the assessment of fetal hypoxia, and its availability near all delivery rooms can help in comprehensive care of neonates at community level. There is a pressing need for further research for optimising the test and for its wider application in various settings.

\section{References}

1. Lawn JE, Manandhar A, Haws RA, Darmstadt GL. Reducing one million child deaths from birth asphyxia - a survey of health systems gaps and priorities. Health Res Policy Syst. 2007;5:4. Available from: https://doi.org/10.1186/1478-4505-5-4.

2. Sankar MJ, Neogi SB, Sharma J, Chauhan M, Srivastava R, Prabhakar PK. State of newborn health in India. J Perinatol. 2016;36((Suppl 3)):S3-S8. Available from: https://dx.doi.org/ 10.1038/jp.2016.183.

3. Dettrick Z, Jimenez-Soto E, Hodge A. Socioeconomic and geographical disparities in under-five and neonatal mortality in Uttar Pradesh, India. Matern Child Health J. 2014;18(4):960-9. Available from: https://dx.doi.org/10.1007/s10995-013-13248. 
4. Rotich SK, Ndavu MP, Rukaria-Kaumbutho R, Kigondu CS. Early perinatal outcome in cases delivered through caesarian section following clinical diagnosis of severe foetal distress at Kenyatta National Hospital. East Afr Med J. 2006;83(5):250 258. Available from: https://dx.doi.org/10.4314/eamj.v83i5. 9430.

5. Low JA, Victory R, Derrick EJ. Predictive value of electronic fetal monitoring for intrapartum fetal asphyxia with metabolic acidosis. Obstet Gynecol. 1999;93(2):285-91. Available from: https://doi.org/10.1016/s0029-7844(98)00441-4.

6. O'Donnell CPF, Kamlin COF, Davis PG, Carlin JB, Morley CJ. Interobserver variability of the 5-minute Apgar score. J Pediatr. 2006;149(4):486-489. Available from: https://dx.doi. org/10.1016/j.jpeds.2006.05.040.

7. Riley RJ, Johnson JW. Collecting and Analyzing Cord Blood Gases. Clin Obstet Gynecol. 1993;36(1):13-23. Available from: https://doi.org/10.1097/00003081-199303000-00005.

8. Vandenbussche FP, Oepkes D, Keirse MJ. The merit of routine cord blood $\mathrm{pH}$ measurement at birth. J Perinat Med. 1999;27(3):158-65. Available from: https://doi.org/10.1515/ jpm.1999.021.

9. Malin GL, Morris RK, Khan KS. Strength of association between umbilical cord $\mathrm{pH}$ and perinatal and long term outcomes: systematic review and meta-analysis. BMJ. 2010;340(13 1):c1471-c1471. Available from: https://dx.doi. org/10.1136/bmj.c1471.

10. Piquard F, Schaefer A, Dellenbach P, Haberey P. Is fetal acidosis in the human fetus maternogenic during labor? A reanalysis. Am J Physiol . 1991;261(5):1294-1299. Available from: https://doi.org/10.1152/ajpregu.1991.261.5.r1294.

11. Piquard F, Schaefer A, Hsiung R, Dellenbach P, Haberey P. Are There Two Biological Parts in the Second Stage of Labor? Acta Obstet Gynecol Scand. 1989;68(8):713-718. Available from: https://doi.org/10.3109/00016348909006144.

12. Executive summary: Neonatal encephalopathy and neurologic outcome, second edition. Report of the American College of Obstetricians and Gynecologists' Task Force on Neonatal Encephalopathy. Obstet Gyencol. 2014;123(4):896-901. Available from: https://doi.org/10.1097/01.aog.0000445580. 65983.d2.

13. Higgins RD. Hypoxic ischemic encephalopathy and hypothermia: a critical look. Obstet Gynecol. 2005;106(6):1385-1387. Available from: https://doi.org/10.1097/01.aog.0000190206. 70375.b4.

14. Perlman JM. Intervention strategies for neonatal hypoxicischemic cerebral injury. Clin Ther. 2006;28(9):13531365. Available from: https://doi.org/10.1016/j.clinthera.2006. 09.005 .

15. Williams KP, Singh A. The Correlation of Seizures in Newborn Infants With Significant Acidosis at Birth With Umbilical Artery Cord Gas Values. Obstet Gynecol. 2002;100(3):557560. Available from: https://doi.org/10.1016/s0029-7844(02) 02090-2.
16. White CRH, Doherty DA, Henderson JJ, Kohan R, Newnham JP, Pennell CE. Accurate prediction of hypoxic-ischaemic encephalopathy at delivery: a cohort study. J Matern Fetal Neonatal Med. 2012;25(9):1653-1659. Available from: https: //doi.org/10.3109/14767058.2011.653421.

17. Allanson ER, Pattinson RC, Nathan EA, Dickinson JE. The introduction of umbilical cord lactate measurement and associated neonatal outcomes in a South African tertiary hospital labor ward. J Matern Fetal Neonatal Med. 2018;31(10):12721278. Available from: https://doi.org/10.1080/14767058.2017. 1315094.

18. Duhan N, Upadhyay K, Chugh K. Umbilical Cord Blood Lactate as an Indicator of Fetal Hypoxia. Open J Obstet Gynecol. 2017;2(3).

19. Borruto F, Comparetto C, Wegher E, Treisser A. Screening of foetal distress by assessment of umbilical cord lactate. Clin Exp Obstet Gynecol. 2006;33(4):219-241.

20. Natesan S. Routine measurements of cord arterial blood lactate levels in infants delivering at term and prediction of neonatal outcome. Med J Malaysia. 2016;71(3):131-134.

21. Gjerris AC, Stær-Jensen J, Jørgensen JS, Bergholt T, Nickelsen C. Umbilical cord blood lactate: A valuable tool in the assessment of fetal metabolic acidosis. Eur J Obstet Gynecol Reprod Biol. 2008;139(1):16-20. Available from: https://doi. org/10.1016/j.ejogrb.2007.10.004.

22. Labrecque L, Provençal M, Caqueret A, Wo BL, Bujold E, Larivière $\mathrm{F}$, et al. Correlation of Cord Blood $\mathrm{pH}$, Base Excess, and Lactate Concentration Measured With a Portable Device for Identifying Fetal Acidosis. J Obstet Gynaecol Can. 2014;36(7):598-604. Available from: https://doi.org/10.1016/ s1701-2163(15)30539-9.

23. Linet T, Laporte J, Gueye H, Boog G. Micro volume dosage of lactate in cord blood for the evaluation of the neonatal wellbeing. J Gynecol Obstet Biol Reprod (Paris). 2002;31(4):352359.

24. Racinet C, Richalet G, Corne C, Faure P, Peresse JF, Leverve $\mathrm{X}$. Diagnosis of neonatal metabolic acidosis by eucapnic pH determination. Gynecol Obstet Fertil. 2013;41:485-92. Available from: https://doi.org/10.1016/j.gyobfe.2013.07.020.

25. Allanson ER, Waqar T, White CRH, Tunçalp Ö, Dickinson JE. Umbilical lactate as a measure of acidosis and predictor of neonatal risk: a systematic review. BJOG. 2017;124(4):584 594. Available from: https://doi.org/10.1111/1471-0528. 14306.

26. Tuuli MG, Stout MJ, Shanks A, Odibo AO, Macones GA, Cahill AG. Umbilical Cord Arterial Lactate Compared With $\mathrm{pH}$ for Predicting Neonatal Morbidity at Term. Obstet Gynecol. 2014;124(4):756-761. Available from: https://dx.doi.org/10. 1097/AOG.0000000000000466.

27. Patil SS, S, Rath S, George CE. Study on umbilical cord arterial blood gas analysis and cord blood lactate levels as predictors for adverse neonatal outcome: an observational study. Int J Reprod Contracept Obstet Gynecol. 2018;7(4):1494-1494. Available from: https://dx.doi.org/10.18203/2320-1770.ijrcog20181342. 
Copyright: (C) the author(s), 2020. It is an open-access article distributed under the terms of the Creative Commons Attribution License (CC BY 4.0), which permits authors to retain ownership of the copyright for their content, and allow anyone to download, reuse, reprint, modify, distribute and/or copy the content as long as the original authors and source are cited.

How to cite this article: Ananya A, Kumari PML K, Vijayalakshmi B, Chandrasekhar R, Kolli NS. Correlation of Cord Lactate with Cord $\mathrm{pH}$ as a Morbidity Predictor in Term Neonates Delivered with Non-Reassuring Fetal Heart Status. Asian J. Clin. Pediatr. Neonatol. 2020;8(3):17-22.

DOI: dx.doi.org/10.47009/ajcpn.2020.8.3.4

Source of Support: Nil, Conflict of Interest: None declared. 